\title{
PERFORMANCE BASED COUPLED CFD-FEM ANALYSIS OF 3-BAY HIGH INDUSTRIAL HALL UNDER NATURAL FIRE
}

\author{
Michal Malendowski, Adam Glema, Wojciech Szymkuc \\ Poznan University of Technology, Institute of Structural Engineering, Poznan, Poland
}

\begin{abstract}
In this paper, the main emphasis is put into showing differences between standard fire design of structural elements and performance based approach, that takes into account analysis of structure under natural fire. The exemplary structure is a 3-bay $65,0 \times 110,0 \mathrm{~m}$ in plane and $22,0 \mathrm{~m}$ high industrial hall with heavy cranes. Because of the significant volume with respect to fire load, there is a low probability that the fully developed fire can occur, nonetheless regarding technological process, a significant local fire could take place and affect the neighbour structure. The most complex approach used in this work is based on coupled CFD-FEM analysis of influence of local fire onto structure.Fire exposure of structural elements is calculated by the coupling scripts, taking into account real heat exposure of section by using adiabatic surface temperature approach.
\end{abstract}

Keywords:Natural fire, CFD-FEM, fire engineering, performance based design

\section{INTRODUCTION}

The structure is a 3 bay steel hall with the height about $21 \mathrm{~m}$ and the bay span about $21,5 \mathrm{~m}$. Main load-bearing frames are composed of built-up steel columns that support a crane girders, floors and roof's trusses. The structure has been already designed according to standard Eurocode rules. Columns are made of I-section chords and hollow section lacings, while the roof trusses are whole made of hollow sections. Above the level of cranes, columns become single I-sections. The geometry of the frame is shown in Fig. 1.

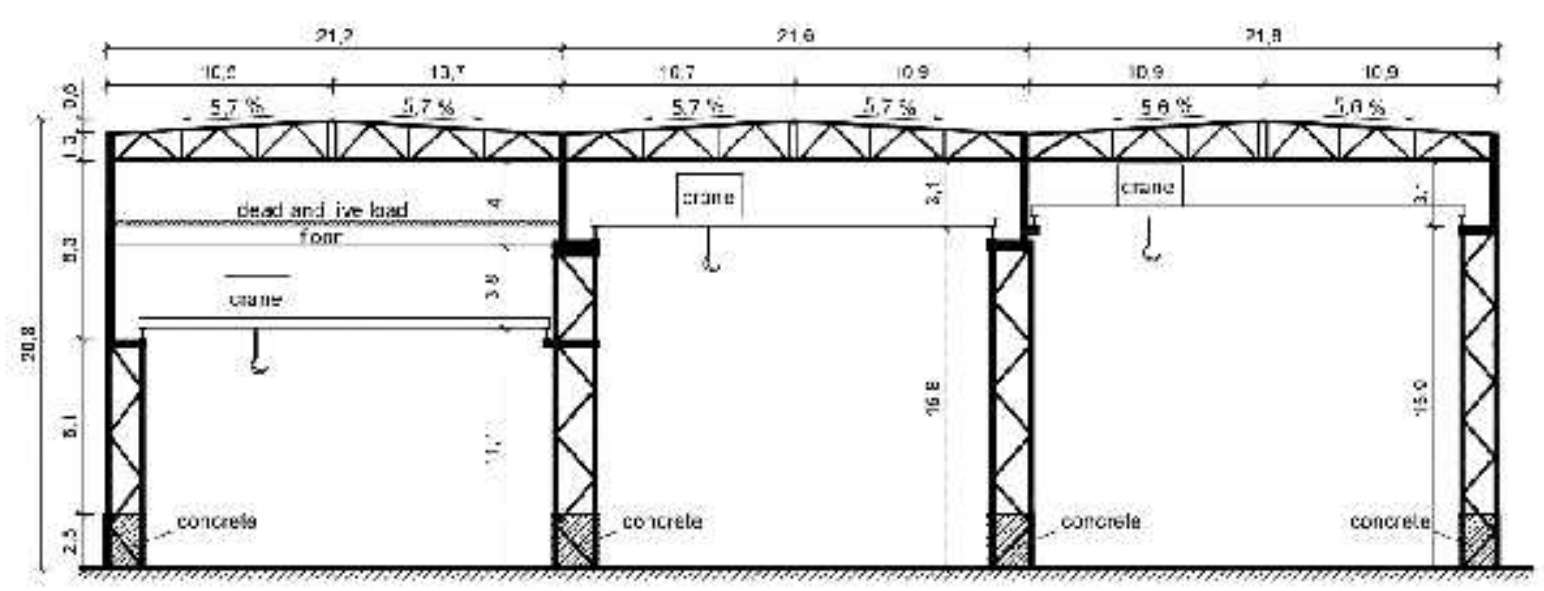

Fig 1 . Sketch of the frame being analysed

\section{ACCIDENTAL COMBINATIONS OF ACTIONS}

All combinations of actions are set up using the regulations given by Eurocode 1990. Permanent loads are collected in such a way, that takes into account the most severe position of cranes during fire. Since this analysis considers only the fire conditions, it is assumed that no technological process is going on in the hall for this design situation. Therefore only the self-weight of both cranes and runway beams is supposed to act on the structure in these conditions. Imposed load is applied only as the live load existed on the floors in "office" area. 
Finally, after adding snow and wind actions, combinations of actions in accidental situation are selected and analyses are carried out according to them. Combinations are collected according to Eq. 6.11a/b in Table A1.3 from Eurocode1990 (EC 1990, 2002), what results in 8 combinations.

\section{FIRE LOAD}

The fire load has been chosen regarding to technological process carried on in the facility. In this case, the most severe action for a structure is the forklift fire in the vicinity of structural column. According to technical documentation of this hall, the truck used in workshop is the "Kalmar DCD 220-12". Because of the lack of information about the fire load and heat release rate for such kind of machines, those data is estimated according to the test conducted for ordinary vehicles (European Commision, 1999a,b; Janssens, 2008).

\subsection{Total heat}

Generally, forklifts used in industry differ significantly from ordinary cars that has been used in tests mentioned above. So that, even if the total mass of "Kalmar DCD 220-12" is approximately about 3,5 tons, it is assumed, that the mass of combustible materials there do not exceed $320 \mathrm{~kg}$, what correspond to the category 3 according to (Zhao, B. \&Kruppa, J., 2004). In this case the total energy released is approximately $9500 \mathrm{MJ}$.

\subsection{Rate of heat release}

Derivation of the heat release rate curve is rather a hard task. In design,the most often used shape of heat release rate curve is this reported by (Zhao, B. \&Kruppa, J., 2004) who gave the curve both for old and new generation cars of category 3 . These curves differs mostly by the peak value of rate of heat release, In this work the curve given for new type of car is simplified and reproduced in order to get the total fire load equal to $9500 \mathrm{MJ}$ and keep the shape of heat release rate.

\subsection{Fire spread}

It is assumed, that fire starts in the place of forklift truck and spread over the domain with the velocity equal to $0,003 \mathrm{~m} / \mathrm{s}$. This approach is just an engineering simplification for fire design purpose. After about one hour of fire, the total area engulfed by fire will be approximately 183,2 $\mathrm{m}^{2}$. It is assumed that the fire spread over the compartment with the rate of heat release per unit area equal to $50,0 \mathrm{~kW} / \mathrm{m}^{2}$, what finally ends up with $26109 \mathrm{MJ}$ of the total energy released after $80 \mathrm{~min}$. Final function of heat release rate is shown in Fig. 3.

\section{CFD MODEL}

CFD model is created in Fire Dynamics Simulator (FDS) software (McGrattan et al., 2014). The goal of this work is to analyse the fire resistance of structure, so fire scenarios is chosen in such a way, to get the worse conditions for structure. Therefore only the fire in technological zone is under consideration. The computational domain is about $110,0 \mathrm{~m} \times 65,0 \mathrm{~m}$ in plane and $27,0 \mathrm{~m}$ height. External domain boundaries are open, what means that there is a free air income and outcome from boundaries. No specific wind and pressure conditions are chosen. $30 \mathrm{~cm}$ mesh is chosen as the most rational one.All external and internal walls and obstacles are defined taking into account the material parameters being a function of temperature (non-linear). Cross-obstacle heat transfer is switched on, so the heat can propagate from one side to another.Because of the difference between the CFD and FEM modelsstructural elements are not directly modelled in CFD model. Therefore, external coupling method is used, which bases on the data provided by CFD analyses.

\section{MECHANICAL MODEL}

The behaviour of structure in fire is simulated by 2D model of one of the main frames, using Abaqus software. Structural elements are modelled as beam elements with local stiffness matrices integrated at each step of analysis. Non-uniform temperature field is taken into account and the 
material parameters of steel varies within the cross-section. Temperature in sections in plane is interpolated according to three temperature points and then sectional stiffness is integrated using Simpson method in five integration points (Abaqus documentation, 2014). Mechanical simulation of structure in fire takes into account both geometrical and material non-linearities. Imperfections are applied into the model by incorporation of first five modes of natural vibration multiplied by the factor of $0,01 \mathrm{~cm}$. The implicit solver is used with slight stabilization of dissipated energy in order to avoid premature stop of analyses caused by minor instabilities of individual finite elements. Boundary conditions are specified in term of fixed support at the base of columns, external forces (nodal and equally distributed) and temperature field inside elements' cross-sections. In order to specify the temperature inside the cross-section external subroutine is created, that reads the output from the coupling scripts and transfer it into mechanical model.

\section{HEAT TRANSFER MODEL}

Considering significant differences between dimension of bar structural elements and size of CFD grid, it is impossible to accurately include structural steel elements in CFD model. Therefore, in this work, structural members are not included into CFD model at all, and heat transfer into the structural members is provided by external model.

Calculations of the heat transfer from gas into the solid phase are based on the concept of adiabatic surface temperature (Wickström et al., 2007), where instead of transferring quantities as gas temperature and heat fluxes under several direction, one single variable is chosen to describe the fire exposure of element, namely adiabatic surface temperature (AST). Because fire exposure substantially depends on the direction of radiation, also here it is considered. AST is collected from four directions which close the cross-section of element inside the virtual box with boundary conditions on its edges, see Fig.4.

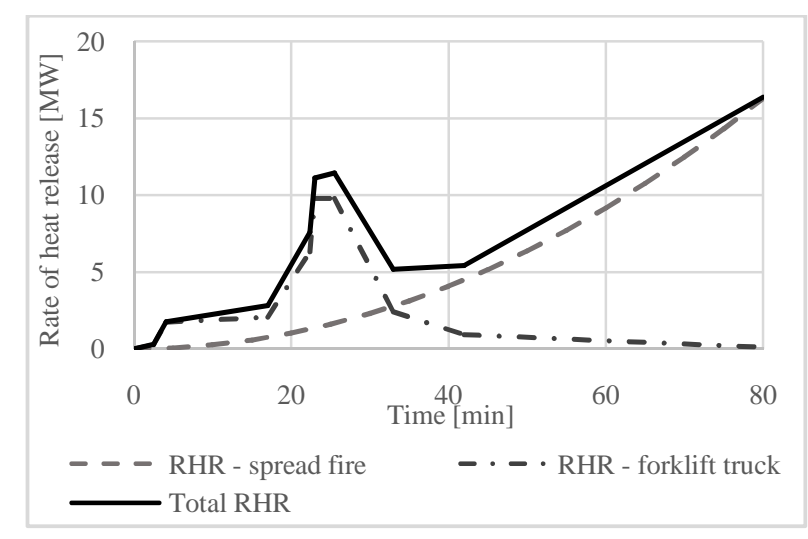

Fig. 3 Rate of heat release used in CFD model

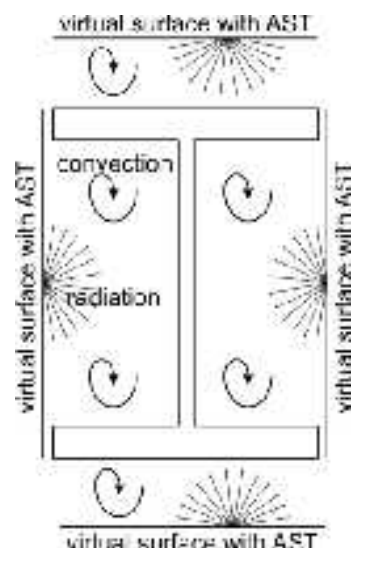

Fig. 4 Scheme of boundary conditions for heat transfer analysis

\section{FIRE RESISTANCE ANALYSES}

As a result of analysis, the comparison between three different approaches is presented. The first approach refers to the simple calculation model given in Eurocode 1993-1-2. So the critical temperature is calculated for each members, like they would be separated and their thermal elongation do not influence the others.Second approach is based on structural analysis of the whole system exposed to ISO-834 fire curve. Temperature of each member is calculated and the 2D model of the whole frame is load by the temperature histories appropriate for each element. The temperature field inside the cross-sections of members is then uniformly distributed. The resultant fire resistance time is taken as the time on which structure lose its stability by changing into mechanism. The third analysis is the most complex one, which takes into account the natural fire that corresponds with selected fire scenario. In order to do it, coupled CFD-FEM analysis is carried on, with one-way sequential coupling which is based on own scripts discussed in previous sections. 


\subsection{Eurocode simple calculation model}

Generally, according to EC simple calculation model, the critical temperatures varies from $350^{\circ} \mathrm{C}$, for the most utilized members in compression, up to more than $1000^{\circ} \mathrm{C}$, for some of members being in tension. Nevertheless, most of the members achieve the critical temperature about $600^{\circ} \mathrm{C}-700^{\circ} \mathrm{C}$, what is rather much and reflects the fact, that this structure carry on significantly reduced load in accidental combinations of actions.

\subsection{Structure under ISO-834 fire}

Here, behaviour of the whole structure depends on particular combination of actions. Three failure mechanisms are recognized and shown in Fig. 5. Although, in most of the combinations only first bay collapses, and others maintain its load-bearing capacity, two other combinations show that roof trusses are sensitive for failure and collapse process may start there as well.

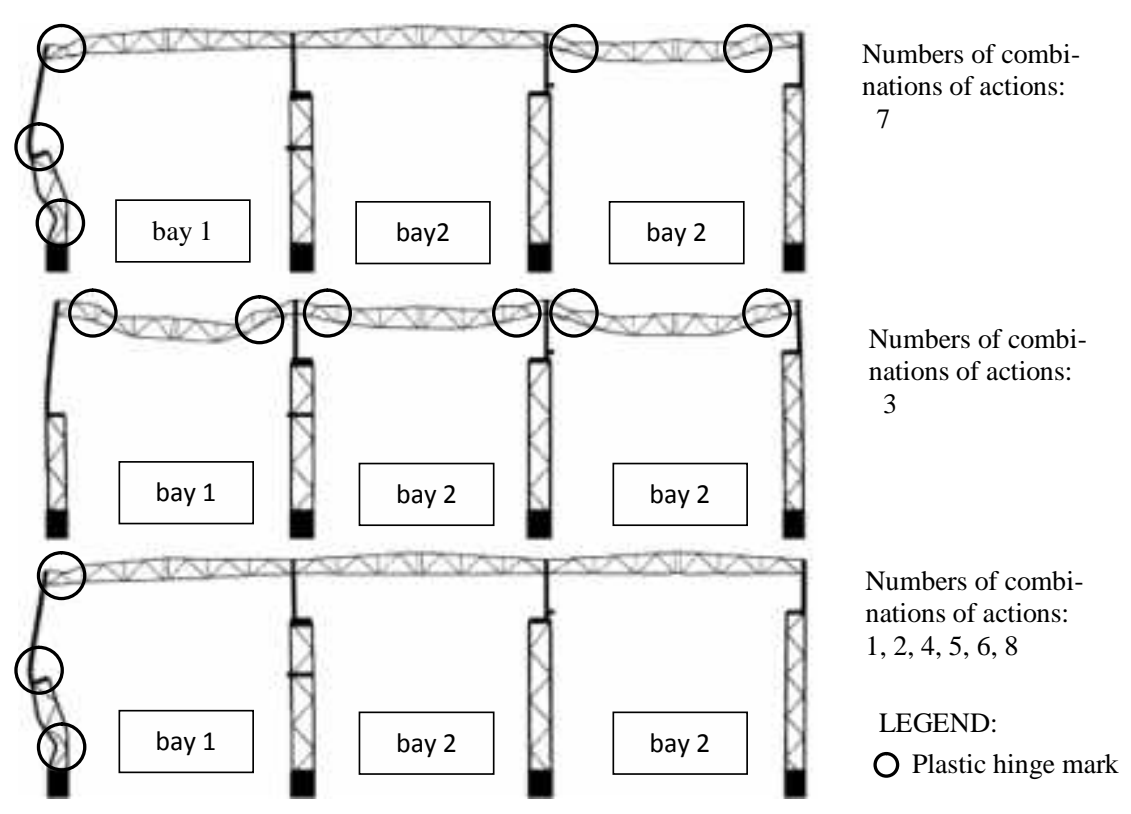

Fig.5 Failure mechanisms with respect to combinations of actions

The particular fire resistance times (time to failure) for each combination of actions are shown in Table 1. The most unfavourable is combination 3, where the failure in bay 3 occur after about 12 min. of fire. Because in all of the combinations where bay 1 collapses first, the numerical problem becomes unstable before the collapse of other parts, there is no info about the time of collapse of them. Fire resistance time about 12-15 min. strictly corresponds with the temperature of elements about $550-650^{\circ} \mathrm{C}$ (depending of section), what is generally about $50^{\circ} \mathrm{C}$ less than the mean critical temperatures obtained from Eurocode simple calculation model.

Table 1.Fire resistance time for each combinations of action and each bay

\begin{tabular}{|c|c|c|c|}
\hline \multirow{2}{*}{$\begin{array}{c}\text { Comb. of } \\
\text { actions }\end{array}$} & \multicolumn{3}{|c|}{ Fire resistance time } \\
\cline { 2 - 4 } & Bay 1 & Bay 2 & Bay 3 \\
\hline $1,2,4-7,8$ & average $820 \mathrm{sec} .(13,6 \mathrm{~min})$. & no info & no info \\
\hline 3. & $830 \mathrm{sec} .(13,8 \mathrm{~min})$. & $811 \mathrm{sec} .(13,5 \mathrm{~min})$ & $706 \mathrm{sec} .(11,8 \mathrm{~min})$ \\
\hline 7. & $867 \mathrm{sec} .(14,5 \mathrm{~min})$ & no info & $840 \mathrm{sec} .(14,0 \mathrm{~min})$. \\
\hline
\end{tabular}

Generally, the well-known behaviour of uniformly heated structure can be observed. First, thermal expansion of material plays the main role and structure expands. At about 8-9 minute of fire material's parameters degrades to the level, when thermal expansion potential reaches the level of bearing capacity of structure, so structure steadily keep its shape. Internal forces are redistributed 
over the structure and plastic hinges start to develop. Then, when fire resistance is reached, there is a rapid failure of structure (or its part), because of the mechanism that occurred. It can be seen in Fig.6.

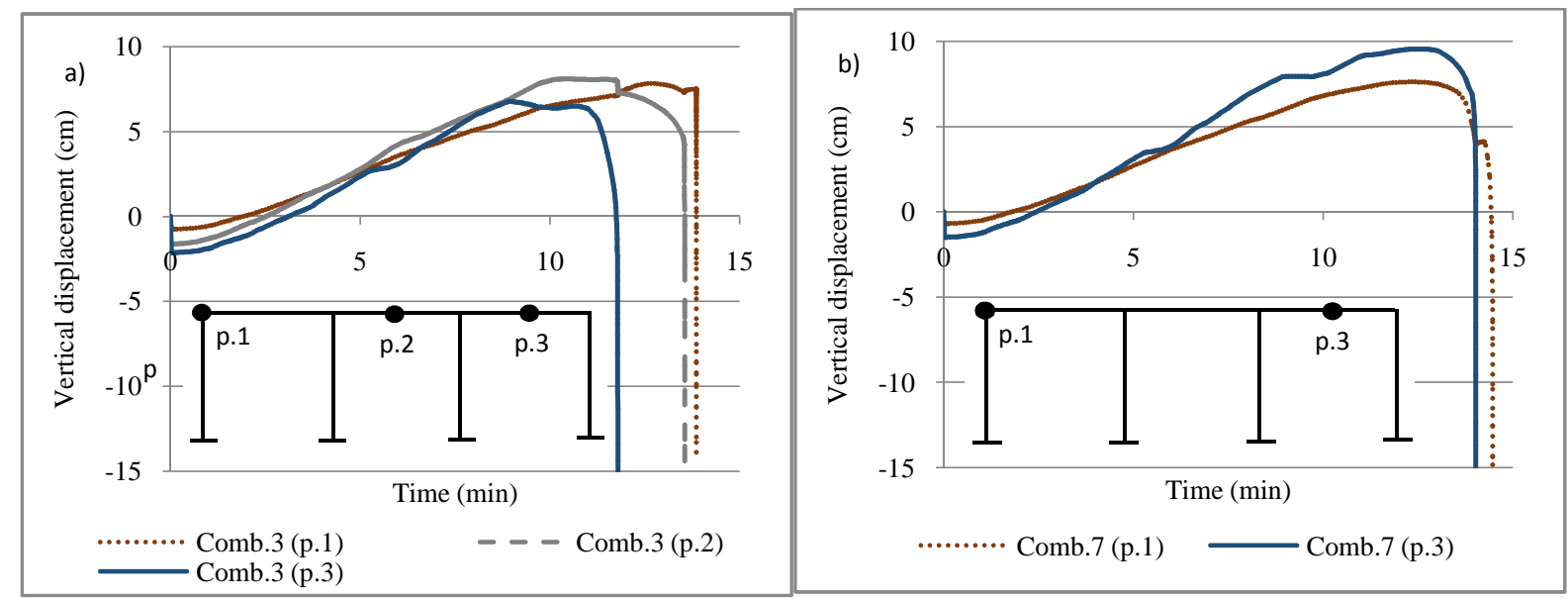

Fig.6 Time-Vertical displacement graphs for: a) third comb. of action; b) seventh comb. of action

\subsection{Structure under natural fire}

In case of natural fire, temperatures for introduced fire scenario are significantly less than these obtained according to ISO-834 fire curve. Open gates in bay under fire causes the free inflow of free air and no other active fire protection measures need to be used. Temperatures generally do not exceed $170^{\circ} \mathrm{C}$, but thermal radiation in the vicinity of fire can be much higher. Depending on the location, the real temperature exposure, in term of adiabatic surface temperature, can be even $25 \%$ higher, than by just taking into account the gas temperature (AST). These fact is shown in Fig. 8 , where the percentage ratio between AST and gas temperature is summarized for 4 different points. Therefore the adiabatic surface temperature concept is used in order to specify boundary conditions at the structural surfaces.

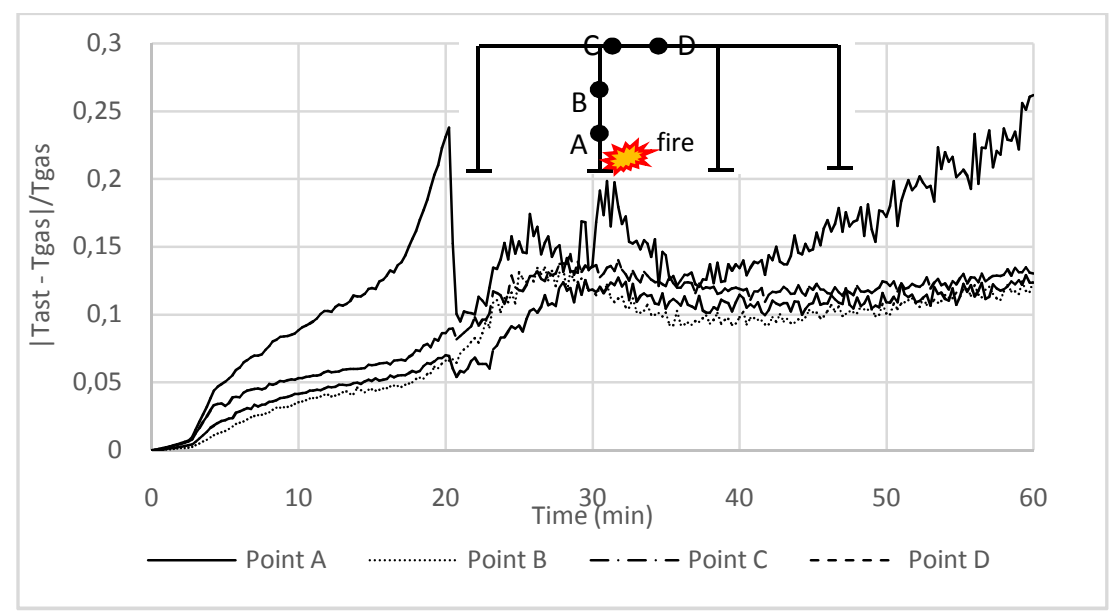

Fig. 8 Percentage ratio between adiabatic surface temperature and gas temperature

For a column which is directly exposed for a local fire, temperatures that reach the external flanges of truss differ about $20^{\circ} \mathrm{C}$ between each other, what is about $16 \%$ of the mean temperature at that region. That cause additional thermal bending of column, which for higher temperatures can be even much significant. The whore case may be observed for a situation where there will be an obstacle wall located in the centre of truss column. Then this bending caused by temperature gradient may be the main reason of failure. An example of such behaviour is shown in Fig. 9, where for ISO-834 exposure (Fig. 9a) all parts of structure elongate in the same rate and frame rise outwards, while in structure exposed to localised fire, the thermal expansions of particular parts are 
different and the behaviour differs. In this example it is clearly visible, that right part of the frame in Fig. 9 is barely affected by temperature and resist the mechanical actions caused by elevated temperature developed in other parts of structure, while the column affected directly by fire bends itself and deflection is propagated into the weaker left part of frame.

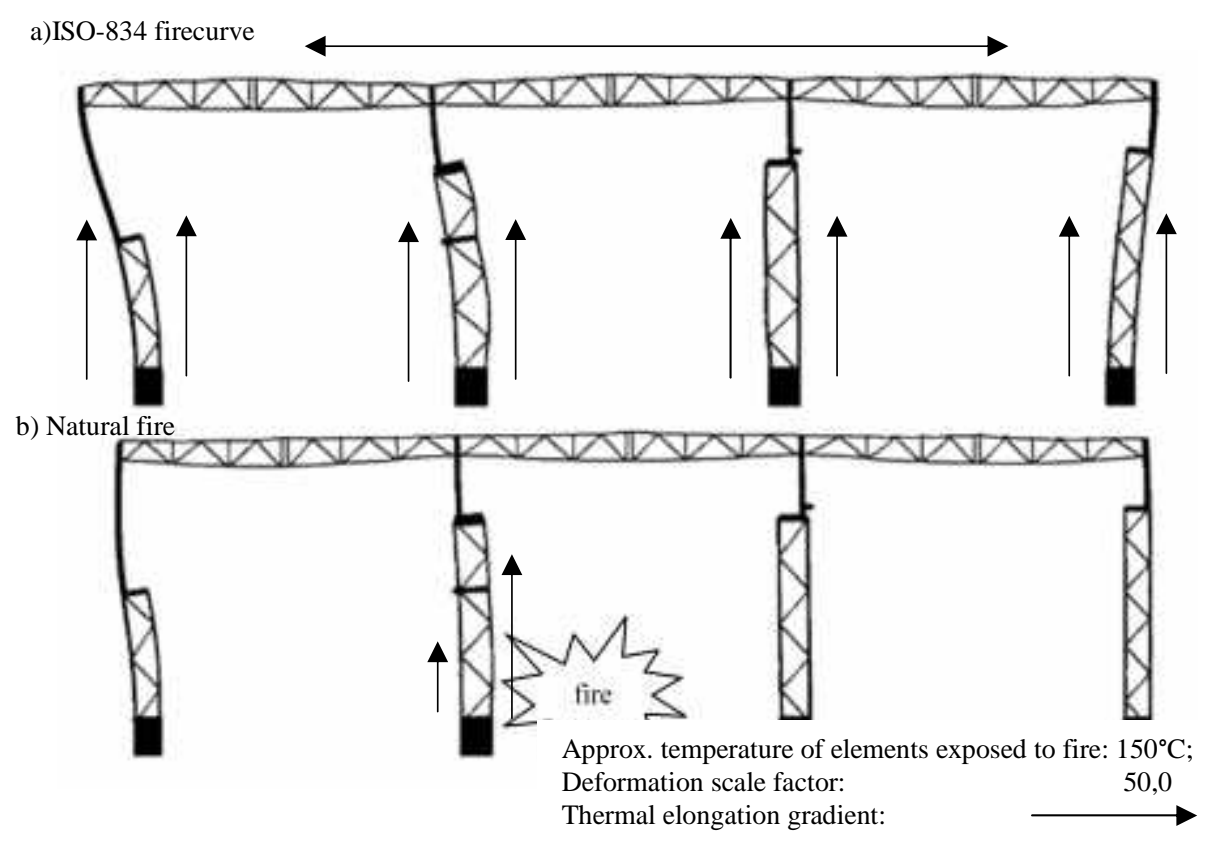

Fig. 9 Differences between the behaviour of structure exposed to ISO-834 fire and natural fire

\section{CONCLUSIONS}

In this work, the significant difference between three different structural fire engineering approaches has been shown on the example of the industrial hall. It has been emphasized, that the standard design, especially in this particular case, based on single element fire resistance calculation, as well as the design based on the analysis of the whole frame under ISO-834 fire curve overestimates the real needs for assuring the performance of the structure in fire. Nevertheless, this work has shown also, that during the coupled CFD-FEM analyses of structure under localised fire, the fire exposure of structural elements must be calculated with consideration of both gas temperature and radiation temperature, what can be set together in one quantity called adiabatic surface temperature. Without such consideration, the results from these analyses can underestimates the elements' temperature and lead to unsafe design. Nonetheless, future examination of this example should focus on different fire scenarios and heat release rate histories in order to draw more comprehensive and quantitative conclusions from performance based design based on coupled CFD-FEM analyses.

\section{REFERENCES}

DassaultSystèmes, Abaqus Documentation, 2014.

European Committee for Standardization, 2002. Eurocode 1990 - Basis of structural design.

European Commission, Technical Steel Research group, 1999. Development of design rules for steel structures subjected to natural fires in closed car parks, Luxembourg: European Commission.

European Commission, Technical Steel Research group, 1999. Development of design rules for steel structures subjected to natural fires in large compartments, Luxembourg: European Commission.

Janssens, M., 2008. Development of a Database of Full-Scale Calorimeter Tests of Motor Vehicle Burns, San Antonio, Texas, USA: Southwest Research Institute.

McGrattan, K. et al., September 30, 2014. Fire Dynamics Simulator, User's Guide. NIST Special Publication 1019, Sixth Edition. National Institute of Standards and Technology.

Wickström, U., Duthinh, D. \&McGrattan, K., 2007. Adiabatic surface temperature for calculating heat transfer to fire exposed structures, Proceedings of International Interflam Conference XI. 
Zhao, B. \&Kruppa, J., 2004. Structural Behaviour of an Open Car Park Under Real Fire Scenarios. Fire and Materials, Issue 28, pp. 269-280. 